\title{
GMR
}

\section{Molecular markers located on the DGAT1, CAST, and LEPR genes and their associations with milk production and fertility traits in Holstein cattle}

\author{
R. Hill, A. Canal, K. Bondioli, R. Morell and M.D. Garcia \\ School of Animal Sciences, Louisiana State University, LSU AgCenter, \\ Baton Rouge, LA, USA \\ Corresponding author: M.D. Garcia \\ E-mail: Mgarcia@agcenter.Isu.edu \\ Genet. Mol. Res. 15 (1): gmr.15017794 \\ Received October 6, 2015 \\ Accepted January 6, 2016 \\ Published March 31, 2016 \\ DOI http://dx.doi.org/10.4238/gmr.15017794
}

ABSTRACT. The objective of the present study was to investigate single nucleotide polymorphisms (SNPs) located in three candidate genes previously reported to have effects on fertility and milk production traits in a population of 123 Holstein cows. The milk production traits evaluated included lifetime averages of milk yield, protein concentration, and fat concentration. Fertility traits evaluated included lifetime averages of services per conception and days-open. Candidate genes included those encoding diacylglycerol acyltransferase (DGAT1), leptin receptor (LEPR), and calpastatin (CAST). A total of 60 SNPs were selected (20 per gene) at equidistant locations on each candidate gene to identify potential linkage with causative mutations. Four SNPs were identified as being significantly associated with the evaluated fertility traits. Specifically, SNPs rs 109663724 and rs 137673193 were significantly associated with lifetime average days-open, while rs109663724 and rs135560721 were significantly associated with lifetime average number of services per conception. Five SNP (rs109663724, rs132699547, rs135423283, 
rs135576599, and rs13675432) were significantly associated with lifetime averages of milk protein concentration and milk fat concentration, with only one SNP (rs109663724) being significantly associated with the average lifetime milk yield. Although multiple SNPs were identified in the current study as being significantly associated with milk production and fertility traits, it is essential that these SNPs are validated in larger populations, under more diverse environments, and that additional SNPs and candidate genes are evaluated prior to their implementation into selection strategies.

Key words: SNP; Milk; Candidate gene; Cattle; Holstein; Fertility

\section{INTRODUCTION}

Dramatic improvements in milk yield have been observed over the past five decades (Butler and Smith, 1989; Washburn et al., 2002), and modern Holstein cattle are now producing significantly more milk than in previous decades. The lactation cycle is initiated and renewed by parturition; therefore, an animal must have the ability to conceive, maintain a pregnancy, and rebreed in a timely manner (Lucy, 2001). However, over recent decades, the major focus of selection in Holstein cattle has continued to center on increasing milk production. Consequently, over the same time period, a dramatic decline in reproductive efficiency has been reported in female Holstein. Washburn et al. (2002) reported that days-open and services per conception in Holstein cattle had increased from 124 to 168 days and 1.91 to 2.94, respectively, between 1976 and 1999. However, milk yield increased from 4753 to $6375 \mathrm{~kg}$ and fat yield increased from 228 to $282 \mathrm{~kg}$ during the same period.

Identification of single nucleotide polymorphisms (SNPs) located in candidate genes or regions of the genome reported to be associated with milk production and fertility traits may provide researchers and producers with a method that can be used to increase the accuracy of selection for lowly heritable traits like fertility while maintaining or improving milking ability. Three candidate genes of known physiological function were selected for investigation in the current study. The leptin receptor (LEPR), calpastatin (CAST), and diacylglycerol acyltransferase genes (DGAT1) were selected based on previously reported associations with fertility and milk production traits in Holstein cattle (Liefers et al., 2002; Ashwell et al, 2004; Garcia et al., 2006). The three candidate genes utilized in the current study have been associated with triglyceride synthesis (Thaller et al., 2003), expression in the mammary glands (Bartha et al., 2005), first service per conception (Clempson et al., 2011), and polymorphisms associated with daughter pregnancy rate (DPR) in dairy cattle (Garcia et al., 2006).

The objective of the current study was to evaluate potential SNP associations in three candidate genes with fertility and milk production traits in a population of Holstein cows located in the southeastern United States.

\section{MATERIAL AND METHODS}

Experimental procedures were approved and performed in accordance with the International Animal Care and Use Committee guidelines for the use and care of animals in agricultural research (Approval No. AE-2009-21). A total of 123 female Holsteins born between 2004 and 2010 at the Louisiana State University Agricultural Center Research and Teaching Dairy Farm located in Baton 
Rouge, Louisiana, were utilized for the current study. All female Holstein were maintained on a dry mixed diet and were managed and evaluated at the above location. Lactating females were milked twice daily during their lactation cycle and milk production traits were collected and recorded for each individual for future analyses. Average lifetime production was calculated for milk yield, protein yield, fat yield, services per conception, and days-open, owing to animals of different ages varying in the number of lactation cycles.

For breeding purposes, a controlled internal drug release (CIDR) Synch protocol (Accelerated Genetics, Baraboo, WI, USA) was utilized prior to artificial insemination with frozen/ thawed semen to synchronize female Holstein. Females that did not respond to the CIDR Synch protocol were identified by visual heat detection and artificial insemination was repeated during the next observed estrus. Pregnancy status was determined utilizing the rectal palpation technique and subsequent management decisions regarding rebreeding or culling were made.

Blood samples were collected from all female Holsteins via tail vein vena puncture. Blood was transferred to $20-\mathrm{mL}$ tubes and centrifuged at $4000 \mathrm{rpm}$ at $4^{\circ} \mathrm{C}$ for $20 \mathrm{~min}$. White blood cell buffy coats were extracted and transferred to $250-\mu \mathrm{L}$ micro-centrifuge tubes. Genomic DNA was isolated and purified from buffy coats using a previously described saturated salt procedure (Miller et al., 1988). DNA working solutions ( $200 \mu \mathrm{L})$ were prepared by diluting $25 \mathrm{ng} / \mu \mathrm{L}$ stock DNA with Tris EDTA buffer.

Sequences of SNPs located in the candidate genes (CAST, DGAT1, and LEPR) were identified from dbSNP (http://www.ncbi.nlm.nih.gov/projects/SNP/). A total of 20 SNPs per candidate gene were selected by identifying SNPs that were evenly distributed over the entire length of each gene. This selection method was selected to account for possible linkage associations with potential causative mutations located on the candidate genes. Flanking sequences of SNPs and allele substitutions for $L E P R, C A S T$, and DGAT1 are reported in Tables 1, 2, and 3. IPLEX reactions for all SNPs were generated by NeoGen LLC (Lincoln, NE, USA) and genotyping assays were conducted by NeoGen LLC utilizing Sequenom genotyping technology (San Diego, CA, USA). The Sequenom technology is a MassArray platform that utilizes MALDI-TOF technology to detect the specific mass of uniquely amplified SNP alleles.

Table 1. Single nucleotide polymorphism (SNP) ID numbers, allele substitution, and flanking sequences used to amplify and visualize LEPR genotypes.

\begin{tabular}{|c|c|c|c|}
\hline SNP ID & $\begin{array}{c}\text { Allele } \\
\text { substitution }\end{array}$ & Forward primer & Reverse primer \\
\hline rs135977111 & $\mathrm{A} / \mathrm{G}$ & CTTCTGTTCTCTTCCTTGCAAAACATGTAA & CAAGCTCCCTGGCAGTGGGATTTCCAGACA \\
\hline rs133145962 & $\mathrm{A} / \mathrm{G}$ & TATCTTTGGCAGGAATGCAATCAAATGTGT & TTAATCAGTCATGTCTGACTCTTTGTGACC \\
\hline rs43347905 & $\mathrm{A} / \mathrm{G}$ & TTTTCTCTGTGTCTTTTAAATGTCCTAACA & AATTTATTTATGTAATAACTGCATTTAACT \\
\hline rs133109480 & $\mathrm{A} / \mathrm{G}$ & GGTTTACAGTCCATAGAGTCGCAAAGAGTC & GACATAACTGAGCTGCTAAGCTCAAGCACG \\
\hline rs43347912 & $\mathrm{G} / \mathrm{T}$ & CTGGACGGCCAGGGGGTTCCCTGAACTAAT & TTTAAAGTCACCCTAGGAGTAGAACAGATA \\
\hline rs43347914 & $\mathrm{A} / \mathrm{G}$ & AAGCTCTTCCCTGCCTTCCCTTTGATTTTT & CTCAGAAGCCATTTCATAGTTCTAACATTG \\
\hline rs43347917 & $\mathrm{A} / \mathrm{T}$ & TTTAACCAATCCATTGATTTTTAATGTATG & AGTGTAACATTTTCAAATATCAAGTGAAAA \\
\hline rs136901371 & $\mathrm{C} / \mathrm{T}$ & GAGACAAGAGAGAAGAGTTCAGAATAAAAT & GGGCTTGATTAATGGAGCAGAATACTCAAA \\
\hline rs43348634 & $\mathrm{A} / \mathrm{G}$ & CTAAGCTGCTAAGTCACTTCAGTCATGTCC & ACTCTGTGCGAACCCATAGATGGCCTCCCA \\
\hline rs134577752 & $\mathrm{A} / \mathrm{G}$ & CTGAGCACACTTGTTTACTTTACAAATAAC & CATGTTTCTTCTCTCAAAATTTTAGTTGGT \\
\hline rs135915491 & C/G & AGCAGCAAAGTGGTTTGAAAAATTGAAGTA & ATAGTGATCCTCAAGATGTTTTGTGTGCAT \\
\hline rs43348652 & A/G & TCTCTGCCCAGTATTGTCTACCCCTGCTCT & TGAGGCAGGAACTTTGTCTCACTCACCATT \\
\hline rs134375381 & $\mathrm{G} / \mathrm{T}$ & CAAAGACAAGAGCCTTTTGCTTGGAGTAAT & AAGGTAGGAGAACATTCAGAGATGTGGTTA \\
\hline rs135560721 & $\mathrm{C} / \mathrm{T}$ & TTTTGAGGAGATTCAGTCATACTTCAATAT & GTACATTCAAGCTTTCATTCAAGATCAGCA \\
\hline rs137541136 & A/G & GCTATTTCAAATCCTAAAAGATGATGCTGT & AAAGTGTGGCACTCAATATGCCGGCAAATT \\
\hline rs43348655 & $\mathrm{C} / \mathrm{T}$ & ACAGTCCATGGGGTCACAAAGAGTTGGACA & GACTGAGCAAAATCACTTGGTGCTGCATAA \\
\hline rs43348659 & $\mathrm{A} / \mathrm{C}$ & AAGAATAATATTTTAGAGAAATATTGATTC & CCTTGTCCTCGCCACACGACACTGGCACTG \\
\hline rs137111668 & $\mathrm{C} / \mathrm{G}$ & СТСТССТTATTAGAAAATTGTCATTTACTT & ААTTGCATACССАСТTACTGTCAAGCAAAA \\
\hline rs137842817 & $\mathrm{G} / \mathrm{T}$ & AAAGTTTAATTGGATGTTCTGATGGTTTTT & AAATCTGAGTAGTCATAACTCAAAGCTTAG \\
\hline rs135263435 & $\mathrm{A} / \mathrm{G}$ & TACTAGAAGACACTGTGAAAATTCAACTTT & GGAATGACAGCTCCTCATTTTACTAGCTTT \\
\hline
\end{tabular}


Table 2. SNP ID numbers, allele substitution, flanking sequences utilized to amplify and visualize CAST genotypes.

\begin{tabular}{|c|c|c|c|}
\hline SNP ID & $\begin{array}{c}\text { Allele } \\
\text { substitution }\end{array}$ & Forward primer & Reverse primer \\
\hline rs43529864 & G/T & GTGGGAGCCAGCTCGGACGTACACGTGCTA & TCGGCGTGAGTTCAGGCTCACAAGTTGAAT \\
\hline rs133108534 & $\mathrm{C} / \mathrm{T}$ & TTGTCCTATTTTTGATTGCAATGATTCTTT & TTCAGCCTCCTCAAGTCTGCCTTTGAATCC \\
\hline rs134804900 & $\mathrm{A} / \mathrm{G}$ & TCTGAGTGAAATGTCTCCTACTTTAGGACC & GCATCCTGCACTTCCTGTCTTTGCTCCCGT \\
\hline rs109727429 & $\mathrm{C} / \mathrm{T}$ & AGCTGGCTGACAGAGAGGAGAGCCAGGCTT & GCCCTGCTCCCGTGACATAAATCACTGCAG \\
\hline rs133978255 & $\mathrm{G} / \mathrm{T}$ & CACAGAGTCGGACACGACTGAAGCGACTTA & CAGCAGCAGCATACTCTTAACTAGTATCCA \\
\hline rs135802918 & $\mathrm{G} / \mathrm{T}$ & AATTGGTCATTATATCACCACTGCCTAGAG & AGGACCAGGCTTCTAGCCAGGGTTCAGTAA \\
\hline rs134187714 & $\mathrm{C} / \mathrm{T}$ & AATCCCATGGACAGAGGAGCCGCAAAGAGT & GGACAGGAATGAGCCACTTCACTTTCACTT \\
\hline rs135598419 & $\mathrm{A} / \mathrm{C}$ & AGAGCGGTGCTTTGTATCTGTCTTTCAAGA & TGCAAAGTGTTTTCGTGGAGATTTGACAGT \\
\hline rs133440731 & $\mathrm{A} / \mathrm{G}$ & GGGTCACAAAGAGTCAGACATGTCTCAGCA & TCAGACAAACAGCAAGGGTGTTAATGCTTG \\
\hline rs135336850 & $\mathrm{C} / \mathrm{T}$ & ATTCAGTGTTGGCTGAAATTCTACCGGTCT & GAGTCCAGAGTCCGCTCTCGCTCTCTTAGC \\
\hline rs137673193 & $\mathrm{C} / \mathrm{T}$ & CAATTGCACCTGTGGAAGGACAGTCATTAA & ATATAGATAGTGAAAGTGAAACTGTTAGTT \\
\hline rs $110 s$ & $\mathrm{~A} / \mathrm{C}$ & CATCTGTTGATAGACTTATAGGTTGCTTCC & TGTGTTGGCTATTGTAAACAGTGCTTCAAT \\
\hline rs134668965 & $\mathrm{G} / \mathrm{T}$ & $\begin{array}{l}\text { TTATTGTTTTCAGACTGTTGCTAGGATTAT } \\
\end{array}$ & ATCAACCAGACACCAACAGCCATTTCTCTC \\
\hline rs133997237 & $\mathrm{C} / \mathrm{T}$ & AATGAATAAAAGAGCACAGGGCAATCCGTT & ATGAGATGCATTTTATTTGGAAGAGGTGGA \\
\hline rs133149410 & A/G & TAATGTCTCTGCTTTTTAATACCAGGGAAT & TGTTAAATTTCCTCTAGAAAGCTAGCAAAC \\
\hline rs110647227 & A/G & TCCTTAGGCATTCAAGAAAATCATGCTCAC & GCGGGTAGGGTAGCAGACYGTATTGTTGGT \\
\hline rs109491082 & $\mathrm{G} / \mathrm{T}$ & TACAGAGATCGGGCTTCTGAGTCTCATGTT & TCCACCCGGTTTCCATTGCCAAGGACCAAG \\
\hline rs111010631 & $\mathrm{C} / \mathrm{T}$ & ACACACTGAAGGAGCTTAATATATTGTTGC & TTATTAGAATTGAAGTGCAATAATGCATAT \\
\hline rs133820366 & $\mathrm{A} / \mathrm{C}$ & AAGGCCTGCTGTCTCTCTTTCTTCCCCAAC & CCACCACCACCGGTGCTGTTGAGAACGAAG \\
\hline rs136073124 & $\mathrm{C} / \mathrm{T}$ & GCCCTGTGTTTGATTCTACTTTACAGTAAC & GAAGAGCTGGTTTGGATGAGGGAGACTCTG \\
\hline
\end{tabular}

Table 3. SNP ID numbers, allele substitution, and flanking sequences used to amplify and visualize DGAT1 genotypes.

\begin{tabular}{|c|c|c|c|}
\hline SNPID & \begin{tabular}{c|} 
Allele \\
substitution
\end{tabular} & Forward primer & Reverse primer \\
\hline rs134049142 & $\mathrm{A} / \mathrm{G}$ & GGCACCCTGTATGATGAGGGGCATGTGCCA & AGGGTGCCTGTGGCGAGCTCCCCACCTTGC \\
\hline rs135576599 & A/G & CCCCAGGGGATTCATGCAGGGAGGCCGTAG & AGCAGGCAGGGCCAGATGCCCAGCAAGACC \\
\hline rs109711965 & $\mathrm{G} / \mathrm{T}$ & TGCCTGCCCTTTGGTGTGGCAGCCCCTTCA & GCCTCACCTCAGCCTTGGCGCCGGCAGCCT \\
\hline rs134455341 & A/G & GGAAAGGGAGTGGAGATGACCTTGAACACC & TGTCCTTTGCTTTTCTCGGGTCTCTGACCC \\
\hline rs134374261 & $\mathrm{A} / \mathrm{C}$ & GCACAGCCGGGCCGCAGCAGCTGTCAGCCC & CCTGCCGCCCCTGCAAGTCCTGTCTCCCCA \\
\hline rs137617619 & A/G & TGCCCGACTCCTGTGACCCCATGGATTGTA & CCCACCAAGCTCCTCTATCCATGGGATTTTT \\
\hline rs135048973 & $\mathrm{C} / \mathrm{T}$ & ATTGCCACCTAGGAAGCCCССССССССАCC & CCTTTGAATATTCTTGTCTCTTTTCCTTGT \\
\hline rs136875432 & $\mathrm{A} / \mathrm{G}$ & TGCCCCCCTCCTCTTCGGGAGACCATGCAC & TTCTACGCAGCCTGGCACATCTGGCAGACA \\
\hline rs132679620 & $\mathrm{A} / \mathrm{G}$ & TCCTGGGGCCTCGGGGGCAGAGTGTGTGTT & TGCAAAGACAAGGCCATCTGCCAGCAACCC \\
\hline rs132778108 & $\mathrm{C} / \mathrm{G}$ & AGGAGCTGCAGCTTCGGCACCCCCCAACCC & CCCCCCGCCACTCACCCTCGGGTAGGTTCT \\
\hline rs109701809 & A/G & CTGTCTGCCCGCGGGGGTATGTGTATCCTG & TGTCGTGTCCCGGGTTTGCTTGGCCCCTCC \\
\hline rs134718967 & $\mathrm{C} / \mathrm{G}$ & GTGCTCCCTCAACCTCAGGGGCACTCGGGT & ACACCGGGCACAGTCAGGTTAGCAACCCCC \\
\hline rs109663724 & $\mathrm{A} / \mathrm{T}$ & TTGTACCAT & TCTCCATCCAGGGCCGCACCGTGTGTCAGG \\
\hline rs135423283 & $\mathrm{G} / \mathrm{T}$ & TTGGAC & TTCCTGTCAGGGTTTT \\
\hline rs132669273 & $\mathrm{C} / \mathrm{T}$ & CACGAATGTAAGTAC & ATCTGGCTCCTCCC \\
\hline rs109169510 & $A / T$ & GGCTAAGGGGATGTTCCTGCCCAAAAAGGA & GCAGGCAGGGTCTGGTGGGACTTCCTAGTA \\
\hline rs137584522 & $\mathrm{C} / \mathrm{G}$ & AGATGAACCGCTCGGCCGAGGGGGATCCCT & CCCCCACCCCCACTGCGGTCCCGCCGGCTG \\
\hline rs132699547 & $\mathrm{C} / \mathrm{G}$ & GGCCGCCCACCTATCGGGGCAGAGGCAGTA & CAGTGCCCCCATCCCTGGAGCAGGGTCAGG \\
\hline rs134110051 & A/G & ACGGCCGCTGGGCAGCAGGTTTCTTCTGCC & CGGTGGCACAGGCACCTGGGGTTGTGGTTG \\
\hline rs135143198 & $\mathrm{C} / \mathrm{T}$ & GGGGCTCAGCTCACTGTCCGCTTGCTTCCT & CCCCAGCTGTTCCTCACCCAGCTCCAGGTG \\
\hline
\end{tabular}

Animal data were analyzed using the mixed model procedure of SAS version 9.3 (SAS Institute Inc., Cary, NC, USA). The model included independent variables for birth year and individual candidate gene SNPs. Dependent variables fit to the model included average lifetime services per conception, average lifetime days-open, average lifetime milk yield, average lifetime fat yield, and average lifetime protein yield, which were evaluated to test for potential associations 
between SNPs and the previously described traits. Sire was fitted in the model as a random effect. The pdiff function of LSMEANS was utilized to evaluate significant differences in the performance of genotypes for SNPs that were identified as significant. All statistical analyses were conducted using previously described methodologies (White et al., 2005). Any SNP with only one genotype was excluded from the evaluation owing to a lack of genotypic effects. Statistical significance was set at $P<0.05$ and all SNPs reaching this level of significance were reported as being significantly associated with the trait of interest.

\section{RESULTS}

A total of four unique SNPs located on the three candidate genes were found to be significantly associated with the fertility traits of average lifetime days-open, and average lifetime services per conception (Table 4). When evaluating days-open, two unique SNPs were reported, one located on each of the DGAT1 and CAST candidate genes. Animals inheriting the heterozygous genotype for the DGAT1 SNP had significantly longer periods of days-open than animals inheriting the major allele genotype. However, the opposite effect was observed for the significant SNP located in the CAST gene, where animals inheriting the major allele genotype had significantly longer periods of days-open than animals inheriting the heterozygous genotype. A similar effect was observed when evaluating average lifetime services per conception, for which two unique SNPs located on the DGAT1 and LEPR genes were identified as significant $(P<0.05)$. Animals inheriting the heterozygous genotype for the SNP located on the DGAT1 gene had significantly $(P<0.05)$ more average services per conception than animals inheriting the major allele genotype. However, animals inheriting the major allele genotype for the SNP located on the $L E P R$ gene had significantly $(P<0.05)$ more services per conception than animals inheriting the heterozygous genotype of the same gene. No animals in the current study inherited the minor allele genotype for the evaluated SNPs.

\begin{tabular}{|c|c|c|c|c|c|c|}
\hline SNP ID & Trait & Gene & Allele $^{a}$ & Major genotype & $\begin{array}{c}\text { Heterozygous } \\
\text { genotype }\end{array}$ & $P$ value \\
\hline rs109663724 b & Average lifetime DO & DGAT1 & T/A & $114.08 \pm 15.5$ & $251.75 \pm 61.12$ & 0.03 \\
\hline rs137673193 b & Average lifetime DO & CAST & $\mathrm{C} / \mathrm{T}$ & $182.17 \pm 34.42$ & $113.06 \pm 15.64$ & 0.05 \\
\hline rs109663724 ${ }^{\mathrm{b}}$ & Average lifetime services to conception & DGAT1 & T/A & $2.07 \pm 0.11$ & $4.40 \pm 1.12$ & 0.05 \\
\hline rs135560721 ${ }^{\mathrm{b}}$ & Average lifetime services to conception & LEPR & $\mathrm{C} / \mathrm{T}$ & $2.30 \pm 0.14$ & $1.14 \pm 0.33$ & 0.03 \\
\hline
\end{tabular}

${ }^{a}$ Major allele is shown to the left and the minor allele is shown on the left. ${ }^{b}$ All means differ at $\mathrm{P}<0.05$ within a row.

Five unique SNPs were significantly associated $(P<0.05)$ or exhibited a statistical trend for association $(P<0.1)$ with the milk production traits of average lifetime milk yield, average lifetime protein yield, and average lifetime fat yield (Table 5). Furthermore, all significant SNPs were located in the DGAT1 gene, with no animals inheriting the minor allele genotype and no SNP from the other candidate genes being significantly associated with milk production traits. Animals inheriting the major allele genotype for all SNPs had lower levels of average milk yield, average protein yield, and average fat yield as compared with animals inheriting the heterozygous genotype. Furthermore, SNP rs109663724 was significantly associated with both fertility traits evaluated in the current study as well as all evaluated milk production traits. 
Table 5. Performance LSMEANS of SNP located in three candidate genes significantly associated with average lifetime protein yield, average lifetime average milk yield, and average lifetime fat yield in dairy cattle.

\begin{tabular}{|c|c|c|c|c|c|c|}
\hline SNP ID & Gene & Trait & Allele $^{\mathrm{a}}$ & Major allele genotype & Heterozygous genotype & $P$ value \\
\hline \multirow[t]{4}{*}{ rs109663724 } & \multirow[t]{4}{*}{$D G A T 1$} & & T/A & & & \\
\hline & & Protein yield & & $503.21 \pm 20.61$ & $1,172.21 \pm 215.5$ & 0.03 \\
\hline & & Milk yield & & $16,770 \pm 712.84$ & $38,581 \pm 7,452.11$ & 0.005 \\
\hline & & Fat yield & & $659.32 \pm 24.40$ & $1,479.32 \pm 253.42$ & 0.002 \\
\hline \multirow[t]{3}{*}{ rs132699547b } & \multirow[t]{3}{*}{ DGAT1 } & & $\mathrm{C} / \mathrm{G}$ & & & \\
\hline & & Protein yield & & $487.17 \pm 22.55$ & $567.67 \pm 4.40$ & 0.05 \\
\hline & & Fat yield & & $597.53 \pm 26.46$ & $766.68 \pm 47.91$ & 0.002 \\
\hline \multirow[t]{3}{*}{ rs $135423283^{b}$} & \multirow[t]{3}{*}{ DGAT1 } & & $\mathrm{G} / \mathrm{T}$ & & & \\
\hline & & Protein yield & & $486.13 \pm 24.20$ & $576.31 \pm 41.46$ & 0.05 \\
\hline & & Fat yield & & $622.37 \pm 27.11$ & $805.22 \pm 45.79$ & 0.0005 \\
\hline \multirow[t]{3}{*}{ rs135576599 b } & \multirow[t]{3}{*}{ DGAT1 } & & $\mathrm{A} / \mathrm{G}$ & & & \\
\hline & & Protein yield & & $482.52 \pm 24.03$ & $572.80 \pm 40.13$ & 0.05 \\
\hline & & Fat yield & & $623.15 \pm 26.97$ & $789.49 \pm 44.40$ & 0.0006 \\
\hline \multirow[t]{3}{*}{ rs $13675432^{b}$} & \multirow[t]{3}{*}{ DGAT1 } & & $A / G$ & & & \\
\hline & & Protein yield & & $486.52 \pm 24.03$ & $572.80 \pm 40.13$ & 0.05 \\
\hline & & Fat yield & & $623.15 \pm 26.97$ & $789.49 \pm 44.40$ & 0.0006 \\
\hline
\end{tabular}

a Major allele is shown on the left and the minor allele is shown on the left. ${ }^{b}$ All means differ at $P<0.05$ within a row.

\section{DISCUSSION}

The results of the present study support the hypothesis that SNPs located within three candidate genes may be associated with both fertility and milk production traits in the dairy industry. Specifically, two SNPs located in the DGAT1 gene were found to be associated with both average lifetime services per conception and average lifetime days-open. SNPs associated with fertility traits have also been reported in dairy cattle for both the CAST (Liefers et al., 2002) and LEPR genes (Almeida et al., 2008). However, these previous studies identified associations with DPR, longevity, and fertility during early lactation. Furthermore, previous research (de Vries and Veerkamp, 2000) has identified associations between SNPs on the DGAT1 gene with fat/protein ratios during early lactation that had negative effects on dairy cattle fertility. However, to our knowledge, this is the first study that has reported SNPs located on the DGAT1 gene to have direct effects on fertility traits.

It is surprising that no significant associations were found between SNPs located in the LEPR and CAST genes and milk production traits, since both genes have been previously reported to affect multiple production traits in both the beef and dairy industry (Casas et al., 2006; Schenkel et al., 2006; Juszczuk-Kubiak et al., 2008; Komisarek, 2010; Clempson et al., 2011). However, previous studies have also reported candidate genes that are significantly associated with diverse traits such as milk production traits and disease resistance (Wang et al., 2015). The results described herein indicate that five SNPs located in the DGAT1 gene are significantly associated $(\mathrm{P}<0.05)$, or show a statistical trend for association $(P<0.1)$, with milk yield, milk fat, and milk protein. These findings are not surprising, since they are in agreement with those of previous studies that have associated the DGAT1 gene with milk yield, milk protein, and fat yield (Winter et al., 2002; Schenkel et al., 2006).

The current study shows that a single SNP could be associated with multiple complex traits such as fertility and milk production. However, prior to implementing these SNPs into a marker assisted selection strategy, further experimentation is required. SNPs identified in the current study must be evaluated in larger populations and in diverse production environments. Furthermore, a greater number of SNPs and candidate genes must be evaluated in order to identify significant marker associations and SNPs that account for the largest degree of variability for the 
trait of interest. Multiple trait interactions must also be evaluated so that detrimental effects on other economically important traits can be avoided. The identification of numerous SNPs associated with fertility and milk production traits could potentially increase the accuracy of selection for dairy producers trying to incorporate increased performance, profit, and sustainability into their herds.

\section{Conflicts of interest}

The authors declare no conflict of interest.

\section{ACKNOWLEDGMENTS}

The current study was approved and funded by the Louisiana Agricultural Experiment Station through the use of State and Federal Hatch funds.

\section{REFERENCES}

Almeida SE, Santos LBS, Passos DT, Corbellini AO, et al. (2008). Genetic polymorphisms at the leptin receptor gene in three beef cattle breeds. Genet. Mol. Biol. 31: 680-685. http://dx.doi.org/10.1590/S1415-47572008000400013

Ashwell MS, Heyen DW, Sonstegard TS, Van Tassell CP, et al. (2004). Detection of quantitative trait loci affecting milk production, health, and reproductive traits in Holstein cattle. J. Dairy Sci. 87: 468-475.http://dx.doi.org/10.3168/jds.S0022$\underline{0302(04) 73186-0}$

Bartha T, Sayed-Ahmed A and Rudas P (2005). Expression of leptin and its receptors in various tissues of ruminants. Domest. Anim. Endocrinol. 29: 193-202.http://dx.doi.org/10.1016/j.domaniend.2005.03.010

Butler WR and Smith RD (1989). Interrelationships between energy balance and postpartum reproductive function in dairy cattle. J. Dairy Sci. 72: 767-783.http://dx.doi.org/10.3168/jds.S0022-0302(89)79169-4

Casas E, White SN, Wheeler TL, Shackelford SD, et al. (2006). Effects of calpastatin and micro-calpain markers in beef cattle on tenderness traits. J. Anim. Sci. 84: 520-525.

Clempson AM, Pollott GE, Brickell JS, Bourne NE, et al. (2011). Evidence that leptin genotype is associated with fertility, growth, and milk production in Holstein cows. J. Dairy Sci. 94: 3618-3628.http://dx.doi.org/10.3168/jds.2010-3626

de Vries MJ and Veerkamp RF (2000). Energy balance of dairy cattle in relation to milk production variables and fertility. $J$. Dairy Sci. 83: 62-69.http://dx.doi.org/10.3168/jds.S0022-0302(00)74856-9

Garcia MD, Michal JJ, Gaskins CT, Reeves JJ, et al. (2006). Significant association of the calpastatin gene with fertility and longevity in dairy cattle. Anim. Genet. 37: 304-305.http://dx.doi.org/10.1111/j.1365-2052.2006.01443.x

Juszczuk-Kubiak E, Wyszyńska-Koko J, Wicińska K and Rosochacki S (2008). A novel polymorphisms in intron 12 of the bovine calpastatin gene. Mol. Biol. Rep. 35: 29-35.http://dx.doi.org/10.1007/s11033-006-9048-0

Komisarek J (2010). Impact of LEP and LEPR gene polymorphisms on functional traits in Polish Holstein-Friesian cattle. Anim. Sci. Pap. Rep. 28: 133-141.

Liefers SC, te Pas MFW, Veerkamp RF and van der Lende T (2002). Associations between leptin gene polymorphisms and production, live weight, energy balance, feed intake, and fertility in Holstein heifers. J. Dairy Sci. 85: 1633-1638.http:// dx.doi.org/10.3168/jds.S0022-0302(02)74235-5

Lucy MC (2001). Reproductive loss in high-producing dairy cattle: where will it end? J. Dairy Sci. 84: 1277-1293.http://dx.doi. org/10.3168/jds.S0022-0302(01)70158-0

Miller SA, Dykes DD and Polesky HF (1988). A simple salting out procedure for extracting DNA from human nucleated cells. Nucleic Acids Res. 16: 1215.http://dx.doi.org/10.1093/nar/16.3.1215

Schenkel FS, Miller SP, Moore SS, Li C, et al. (2006). Association of SNPs in the leptin and leptin receptor genes with different fat depots in beef cattle. Proceedings of the 8th World Congress on Genetics Applied to Livestock Production 1-4.

Thaller G, Kühn C, Winter A, Ewald G, et al. (2003). DGAT1, a new positional and functional candidate gene for intramuscular fat deposition in cattle. Anim. Genet. 34: 354-357.http://dx.doi.org/10.1046/j.1365-2052.2003.01011.x

Wang W, Cheng L, Yi J, Gan J, et al. (2015). Health and production traits in bovine are associated with single nucleotide polymorphisms in the NOD2 gene. Genet. Mol. Res. 14: 3570-3578.http://dx.doi.org/10.4238/2015.April.17.6

Washburn SP, Silvia WJ, Brown CH, McDaniel BT, et al. (2002). Trends in reproductive performance in Southeastern Holstein and Jersey DHI herds. J. Dairy Sci. 85: 244-251.http://dx.doi.org/10.3168/jds.S0022-0302(02)74073-3 
White SN, Casas E, Wheeler TL, Shackelford SD, et al. (2005). A new single nucleotide polymorphism in CAPN1 extends the current tenderness marker test to include cattle of Bos indicus, Bos taurus, and crossbred descent. J. Anim. Sci. 83: 2001-2008.

Winter A, Krämer W, Werner FAO, Kollers S, et al. (2002). Association of a lysine-232/alanine polymorphism in a bovine gene encoding acyl-CoA:diacylglycerol acyltransferase (DGAT1) with variation at a quantitative trait locus for milk fat content. Proc. Natl. Acad. Sci. USA 99: 9300-9305.http://dx.doi.org/10.1073/pnas.142293799 